\title{
Value-Generating Exploratory Trials in Neurodegenerative Dementias
}

Lauren G. Friedman, PhD, Nicholas McKeehan, BS, Yuko Hara, PhD, Jeffrey L. Cummings, MD, ScD, Dawn C. Matthews, MS, MBA, Jian Zhu, PhD, Richard C. Mohs, PhD, Deli Wang, MMed, PhD, Suzanne B. Hendrix, PhD, Melanie Quintana, PhD, Lon S. Schneider, MD, Michael Grundman, MD, MPH, Samuel P. Dickson, PhD, Howard H. Feldman, MDCM, FRCP(C), Judith Jaeger, PhD, Elizabeth C. Finger, MD, J. Michael Ryan, MD, Debra Niehoff, PhD, Susan L-J. Dickinson, MSGC, Jessica T. Markowitz, PhD, Meriel Owen, PhD, Alessio Travaglia, PhD, and Howard M. Fillit, MD

Neurology ${ }^{\circledR}$ 2021;96:944-954. doi:10.1212/WNL.0000000000011774

\section{Correspondence}

Dr. Fillit

hfillit@alzdiscovery.org

\section{Abstract}

Drug development for Alzheimer disease and other neurodegenerative dementias, including frontotemporal dementia, has experienced a long history of phase 2 and phase 3 clinical trials that failed to show efficacy of investigational drugs. Despite differences in clinical and behavioral characteristics, these disorders have shared pathologies and face common challenges in designing early-phase trials that are predictive of late-stage success. Here, we discuss exploratory clinical trials in neurodegenerative dementias. These are generally phase $1 \mathrm{~b}$ or phase $2 \mathrm{a}$ trials that are designed to assess pharmacologic effects and rely on biomarker outcomes, with shorter treatment durations and fewer patients than traditional phase 2 studies. Exploratory trials can establish go/no-go decision points, support proof of concept and dose selection, and terminate drugs that fail to show target engagement with suitable exposure and acceptable safety profiles. Early failure saves valuable resources including opportunity costs. This is especially important for programs in academia and small biotechnology companies but may be applied to high-risk projects in large pharmaceutical companies to achieve proof of concept more rapidly at lower costs than traditional approaches. Exploratory studies in a staged clinical development program may provide promising data to warrant the substantial resources needed to advance compounds through late-stage development. To optimize the design and application of exploratory trials, the Alzheimer's Drug Discovery Foundation and the Association for Frontotemporal Degeneration convened an advisory panel to provide recommendations on outcome measures and statistical considerations for these types of studies and study designs that can improve efficiency in clinical development.

\footnotetext{
From the Alzheimer's Drug Discovery Foundation (L.G.F., N.M., Y.H., M.O., A.T., H.M.F.), New York; Chambers-Grundy Center for Transformative Neuroscience (J.L.C.), Department of Brain Health, School of Integrated Health Sciences, University of Nevada Las Vegas; ADM Diagnostics (D.C.M.), Inc. Northbrook, IL; Servier Pharmaceuticals (J.Z.), Boston, MA; Global Alzheimer's Platform Foundation (R.C.M.), Washington, DC; AgeneBio (R.C.M.), Inc. Baltimore, MD; AbbVie Inc. (D.W.), North Chicago, IL; Pentara Corporation (S.B.H., S.P.D.), Salt Lake City, UT; Berry Consultants (M.Q.), Austin TX; Keck School of Medicine of the University of Southern California (L.S.S.), Los Angeles; Global R\&D Partners (M.G.), LLC, University of California, San Diego, La Jolla; Department of Neurosciences (H.H.F.), University of California, San Diego, La Jolla; Albert Einstein College of Medicine (J.J.), Bronx, NY; CognitionMetrics (.J.), LLC; Department of Clinical Neurological Sciences and Robarts Research Institute (E.C.F.), Schulich School of Medicine and Dentistry, University of Western Ontario; Parkwood Institute (E.C.F.), Lawson Health Research Institute, St. Josephs Health Care, London, Ontario, Canada; Rodin Therapeutics (J.M.R.), Boston, MA; Association for Frontotemporal Degeneration (D.N., S.L.J.D.), Radnor, PA; and Modus Outcomes LLP (I.T.M.), Cambridge, MA.
}

Go to Neurology.org/N for full disclosures. Funding information and disclosures deemed relevant by the authors, if any, are provided at the end of the article. 


\section{Glossary}

AD = Alzheimer disease ADDF $=$ Alzheimer's Drug Discovery Foundation; ADNI $=$ Alzheimer's Disease Neuroimaging Initiative; AFTD = Association for Frontotemporal Degeneration; ALLFTD = ARTFL-LEFFTDS Longitudinal Frontotemporal Lobar Degeneration; aMCI = amnestic MCI; FDG = fluorodeoxyglucose; FTD = frontotemporal dementia; GENFI = Genetic Frontotemporal Dementia Initiative; MAO-B = monoamine oxidase B; $\mathbf{M C I}=$ mild cognitive impairment; $\mathbf{N f L}=$ neurofilamant light chain; NIMH $=$ National Institute of Mental Health; TSPO $=$ translocator protein.

Alzheimer disease $(\mathrm{AD})$ and other neurodegenerative dementias affect over 50 million people worldwide. ${ }^{1}$ However, no disease-modifying therapies are currently available. Although neurodegenerative dementias may differ in their prevalence, age at onset, and clinical characteristics, they have shared pathologies and common drug development challenges. In particular, clinical trials often require beneficial effects on cognitive, behavioral, and functional end points for approval, which generally entail long treatment periods and large numbers of patients to detect clinically meaningful change. ${ }^{2} \mathrm{AD}$ trials, where more than $99 \%$ have failed to progress to regulatory submission, ${ }^{3}$ are riddled with inefficiencies and prohibitively high costs. The estimated cost for developing an $\mathrm{AD}$ drug is 8 times more than that of a cancer drug and takes nearly twice as long. ${ }^{4,5}$ Inefficiencies also deplete the pool of available clinical trial participants. This is particularly important for uncommon forms of dementia, such as frontotemporal dementia (FTD), where there are significant recruitment challenges. ${ }^{6}$ Recommendations to reduce the cost and size of studies and to accelerate the development of drugs for neurodegenerative dementias have included shortening phase 2 trials and using new strategies to reduce the risk of negative outcomes in phase $3{ }^{4}$ This review centers on clinical study designs to improve efficiency and reduce the overall costs for drug development for neurodegenerative dementias. $\mathrm{AD}$ - the most common form of dementia - and FTD spectrum disorders-an example of rarer dementias-are used here to illustrate recommendations that can be applied to all neurodegenerative dementias, including vascular and Lewy body dementias.

\section{Exploratory Trial Approach}

Using a staged approach that incorporates biomarker-based exploratory studies can inform earlier go/no-go decision points to derisk further development or terminate programs not likely to succeed. We define exploratory studies as earlyphase clinical trials (phase $1 \mathrm{~b}$ or phase $2 \mathrm{a}$ ) designed to assess pharmacologic effects with readouts that help to elucidate the biological activity of a drug in a specific patient population and inform the design of larger regulatory studies. In the case of repurposed or repositioned drugs, exploratory trial data can potentially contribute to building a body of evidence for specific mechanisms of action, leading to new intellectual property through the development of optimized formulations or agents with novel composition of matter that facilitate wellprotected patent positions.
The National Institute of Mental Health (NIMH) has applied such an experimental medicine strategy for psychiatric drugs with its Fast-Fail Trials Program. The initiative aims to more rapidly test novel compounds and identify those that warrant future clinical testing, as well as generating clinical proof-ofmechanism data for repurposed agents. Studies are designed to assess target engagement and biomarker changes that serve as decision points for further testing. The first successful implementation of NIMH's fast-fail approach tested a repositioned א-opioid receptor antagonist (JNJ-67953964) for its potential in treating anhedonia in major depressive disorder and used fMRI activation in the ventral striatum as a measure of target engagement. ${ }^{7}$ Prior research establishing the ventral striatum as involved in decision making, motivation, reinforcement, and reward provided the basis for defining its activation as the primary outcome measure. JNJ-67953964 significantly increased ventral striatum activation during reward anticipation compared with placebo. The positive finding from this study supports advancement to a trial to evaluate clinical efficacy. The inclusion of a pharmacodynamic biomarker (fMRI) in this trial enabled assessment beyond mechanistic target engagement, a relevant but sometimes insufficient step toward achieving targeted evidence of activity.

Similar staged approaches have been used by industry. Eli Lilly and Company's Chorus model is designed to achieve proof of concept more rapidly and at lower costs than traditional approaches, with streamlined early-phase studies that test key clinical hypotheses and assess the potential for clinical benefit (e.g., demonstrating adequate target engagement with an acceptable therapeutic index). Candidates who fail to meet the predefined criteria are terminated early, limiting the progression of assets with lower probabilities of success to substantially more expensive late-stage development activities. ${ }^{8}$

Nonprofit funding agencies, like the Alzheimer's Drug Discovery Foundation (ADDF) and Association for Frontotemporal Degeneration (AFTD), can use a similar approach to enable testing of multiple candidate therapies for $\mathrm{AD}$ and FTD with diverse targets in exploratory trials. Through multiple limited capital investments in distinct early-phase drug programs, nonprofit organizations can apply a multiple shots on goal funding strategy to diversify the therapeutic approaches in the pipeline and to increase the probability of at least one or more advancing to approval. ${ }^{9}$ With smaller investments, positive data from exploratory trials can prioritize 
candidates that warrant further development and catalyze future investments from other investors or partners.

Although exploratory in nature, successful studies at this stage require a rigorous study design with prespecified biomarker outcomes that are relevant to the mechanism of action and, where possible, predictive of clinical efficacy using statistical analyses to make them interpretable and meaningful. To provide guidance for these types of study designs, the ADDF and AFTD convened an advisory panel of clinical trialists, statisticians, neuropsychologists, and biomarker specialists to establish recommendations for academic groups and earlystage biotechnology companies on optimizing exploratory trial designs that will improve the chances of generating clear outcomes for decision making. These recommendations are reflected in the sections below.

\section{Study Design and Statistical Considerations}

Exploratory trials should be designed to answer specific questions about a drug's activity in a specific study population, including whether an intervention is safe, engages its target, induces expected downstream pharmacologic effects, and leads to changes on disease-related measures. Biomarkers should be used to assess relationships to and effects on targets related to the drug mechanism in addition to downstream targets, such as fMRI, that are related to neuronal function and general disease pathology. Ideally, the results of an exploratory study will show significant positive effects on the biomarkers of interest. As part of end point selection, it is important to have established or posited the relationship(s) between the biomarker endpoint and the clinical efficacy measure that will ultimately be required for later phase trials. In particular, target engagement and downstream biomarkers would be important to bridge mechanistic or pathology effects to the expected clinical benefit in the target population.

By definition, exploratory studies are generally small in size and often represent the first time a drug is tested for pharmacologic effects in a patient population. Unlike traditional late-phase studies, which use power analyses based on effect sizes for clinical outcomes from previous trials, a biomarker effect size may not be available when planning an exploratory study. Information on the rate of change and variance of established biomarkers may be obtained from longitudinal cohort studies such as the Alzheimer's Disease Neuroimaging Initiative (ADNI), ${ }^{10}$ Advancing Research and Treatment in Frontotemporal Lobar Degeneration and Longitudinal Evaluation of Familial Frontotemporal Dementia Subjects study, ${ }^{11}$ and the Genetic Frontotemporal Dementia Initiative (GENFI) network. ${ }^{12}$ For biomarkers that have not yet been tested in observational studies, development teams may consider conducting a small nontherapeutic study to obtain these data. Estimation of a minimum important difference for the biomarker can be used to determine the sample size in these early-phase studies.

Overestimating effect size is a common vulnerability in the planning phases of trials, resulting in underpowered studies; this may lead to unresolved questions of the effectiveness of a drug. A danger of small trials with limited sample sizes is that randomization is imperfect and baseline characteristics are not matched. This can lead to over- or under-estimation of the effects of the drug. Statistical adjustments, while post hoc, can help account for baseline imbalances and assist in avoiding erroneous conclusions. ${ }^{10,13}$ For example, the use of mixed effect model analysis with covariates can adjust for baseline imbalances, such as age and baseline cognitive score (and any other variables related to disease severity), and is another means of reducing variability and increasing statistical power.

Advancement from exploratory studies to later-stage development requires well-defined go/no-go criteria with prespecified statistical analyses. This should include analyses of the primary biomarker outcome, as well as analyses assessing the relationship between biomarker response and the response in the expected primary clinical end point that may be used in subsequent phase $2 \mathrm{~b}$ or phase 3 confirmatory studies. Exhaustive exploratory analyses of the data should not be misused to improve the chance of a positive outcome. This approach often generates results that appear to be positive on at least 1 outcome or analysis. For studies that include numerous exploratory outcomes, it may be worthwhile to consult statisticians to apply an adjustment for multiplicity using appropriate procedures. ${ }^{14}$ However, because multiplicity adjustment methods are not applied rigorously at this exploratory phase, the risk for type I error (false-positive findings) remains. At this stage, it may be more relevant to look at the totality of evidence across multiple biomarkers and the directionality of clinical outcomes rather than strict significance on a single predefined outcome. However, investigators should remain wary and skeptical of proceeding with a drug based on a significant positive effect on nonprimary outcomes not directly related to the drug's hypothesized mechanism of action or downstream pharmacologic effects. For studies that do not show reliable effects on outcome measures of target engagement or related downstream biomarker effects, the study sponsors should be prepared to stop further compound development and look for alternative approaches.

Adaptive trial designs, which allow modification of the study design using updated assumptions based on accumulating interim observed data, may be considered to improve trial efficiency and the chance of success when using endpoints that are thought to show robust changes within several months. This can be particularly useful when reliable planning is not possible because data from previous clinical trials are limited or nonexistent. Adaptation features may include sample size re-estimation based on updated knowledge of variance or effect size, adaptive enrichment of a subpopulation, adaptive dosing, or adaptive selection of end 
Table 1 Considerations and Recommendations for Biomarker and Cognitive Outcomes in AD and FTD Exploratory Clinical Trials

\begin{abstract}
$\checkmark$ Include biomarkers that align with the drug's mechanism of action and the stage of disease
- Incorporate direct markers of target engagement where available (e.g., receptor occupancy by PET imaging and inhibition of target in PBMCs)

- Include markers of downstream biological effects (e.g., CSF synaptic biomarkers for a drug with an epigenetic target that promotes synaptic plasticity or FDG-PET for a drug that is predicted to improve glucose metabolism in the brain)
\end{abstract}

- Align the biomarkers that reflect changes in pathology (e.g., amyloid or tau PET in AD trials, volumetric MRI in AD and FTD trials, and plasma NfL)

$\checkmark$ Develop novel target engagement and pharmacodynamic biomarkers in parallel to new candidate therapies in nonclinical development

- Requires preliminary clinical validation data in the target population before including as a trial end point

- Novel biomarkers should be accepted by the development team as suitable for reaching investment decisions

$\checkmark$ Align cognitive, behavioral, and/or functional outcomes with the appropriate clinical domains of the clinical syndrome, stage of disease, and mechanism of action

$\checkmark$ Consider repeated assessments for cognitive outcomes to reduce within-subject variance and improve statistical power

$\checkmark$ Base the study's treatment duration on the expected rate of change for the primary study endpoints and drug mechanism of action

Abbreviations: $A D$ = Alzheimer disease; FDG-PET = fluorodeoxyglucose PET; FTD = frontotemporal dementia; NfL = neurofilament light chain; PBMC = peripheral blood mononuclear cell.

points. The flexibility of adaptive designs also supports randomizing fewer patients to less effective arms, dropping arms completely, extending the trial when results are promising, or stopping early for futility or success. Such adaptation should be prespecified, and appropriate statistical adjustment should be planned to protect trial integrity and preserve statistical validity.

These adaptive features can be implemented via frequentist or Bayesian approaches or a combination of both. Bayesian designs that allow flexible and efficient utilization of data from various sources can be particularly useful in $\mathrm{AD}$ and FTD early clinical development. ${ }^{15}$ For instance, when historical or external data from a similar population are available, information from previous studies can be included as a Bayesian prior in an upcoming trial. If properly adjusted for heterogeneity, historical or external data can potentially reduce the sample size and shorten the timelines. In addition, frequentist methods such as propensity score matching can also be used to combine external data. For instance, subjects from previous studies with similar baseline characteristics and prognostic factors may be matched and then compared with those on the treatment arm in an upcoming trial.

A common misconception outside of industry regarding early-phase AD and FTD drug development is that a statistical evaluation of the appropriate study design may not be necessary due to small sample sizes. However, we suggest that more effort be spent on properly examining the operating characteristics for such trials. Conventional metrics such as statistical power may not directly apply and analytical calculation of metrics such as estimation bias or probability of success may not be available. Thus, a thorough evaluation through simulations based on various assumptions is often necessary to generate a clear understanding of the design advantages as well as risks and caveats. ${ }^{16}$ Carefully planning exploratory studies and basing go/no-go decisions on prespecified outcomes can save investigators from facing disappointing results in more costly, larger, later stage trials. Investigators should engage with statisticians early in the design of an exploratory study as different design options for various purposes can be evaluated simultaneously, and operating characteristics generated for each design can be reviewed by study team members to informatively determine the optimal design.

\section{Outcome Measures}

Selecting the appropriate outcome measures requires careful consideration of the candidate therapy's mechanism of action, the availability of biomarkers and established clinical assessments to measure activity, and the rate of change for end points (table 1). One of the major challenges in developing drugs for $\mathrm{AD}$ and FTD is the lack of reliable target engagement and downstream biomarkers that correlate with the multiple emerging drug targets. Established biomarkers that reflect changes in core pathology include amyloid and tau PET and CSF amyloid- $\beta$, phosphorylated tau, and tau, which are commonly used as biomarker end points in $\mathrm{AD}$ trials. Volumetric MRI is a broad downstream outcome reflecting the effects of many potential mechanisms, including changes in the rate of atrophy, but can also misalign with treatment effects, potentially due to removal of amyloid or reduction of neuroinflammation. Fluorodeoxyglucose (FDG)-PET and fMRI can be used as other downstream markers of target engagement to assess circuit level effects of an intervention. ${ }^{17}$ For example, a recent exploratory study in patients with mild 
Table 2 Comparison of Exploratory and Phase 2b/3 Studies for Disease-Modifying Agents for AD and FTD

\begin{tabular}{lll}
\hline Study goal & $\begin{array}{l}\text { Proof-of-concept, go/no-go decisions for phase 2b, collect data for } \\
\text { future statistical plans }\end{array}$ & Phase 2b/3 studies \\
\hline $\begin{array}{l}\text { Flexible } \\
\text { study } \\
\text { designs }\end{array}$ & $\begin{array}{l}\text { Master protocols, adaptive seamless designs with early go/no-go } \\
\text { decisions, dose dropping, or response adaptive randomization } \\
\text { based on biomarker, Bayesian incorporating external data }\end{array}$ & $\begin{array}{l}\text { Master protocols, adaptive phase 2/3 designs, interim analyses for } \\
\text { early success or futility on clinical outcome measure, and Bayesian } \\
\text { analyses of disease progression modification }\end{array}$ \\
\hline $\begin{array}{l}\text { Main } \\
\text { outcomes }\end{array}$ & Biomarkers that align with the mechanism of action & Cognitive and functional end points \\
\hline $\begin{array}{l}\text { Sample } \\
\text { size }\end{array}$ & $\begin{array}{l}\text { Sample size estimated based on the rate of change and variance of a a } \\
\text { biomarker and estimation of minimum important difference }\end{array}$ & $\begin{array}{l}\text { Sample size determined by power analysis using the drug's effect size } \\
\text { and rate of progression and variance of the primary outcome. Overall } \\
\text { familywise type I error control due to multiple comparisons of } \\
\text { multiple outcomes may also be considered for registration trials }\end{array}$ \\
\hline $\begin{array}{l}\text { Duration } \\
\text { Statistical } \\
\text { analysis }\end{array}$ & Depends on the rate of change of the biomarker & $\begin{array}{l}\text { Depends on the expected time to and duration of anticipated clinically } \\
\text { meaningful outcome }\end{array}$ \\
\hline $\begin{array}{l}\text { Study } \\
\text { results }\end{array}$ & Sufficient information to plan future studies & \begin{tabular}{l} 
Control type 1 error and protect power \\
\hline
\end{tabular}
\end{tabular}

Abbreviations: $A D$ = Alzheimer disease; FTD = frontotemporal dementia.

to moderate $\mathrm{AD}$ used FDG-PET to evaluate the change in cerebral glucose metabolism in patients treated with rasagiline compared with placebo. Rasagiline is a selective monoamine oxidase B (MAO-B) inhibitor that increases the availability of dopamine and is approved for treatment of Parkinson disease. Dopaminergic dysfunction has been associated with cognitive impairment in Parkinson disease as well as $\mathrm{AD}$. By demonstrating improved glucose metabolism in frontostriatal regions consistent with MAO-B inhibiting properties, which correlated directionally with clinical endpoints, the findings from this trial provide a rationale to test rasagiline in a larger study. ${ }^{18}$ The affected neuronal networks and directional clinical effects suggested focus areas for potential benefit. Using exploratory trial outcomes to guide larger study designs may help to address the challenges of mixed outcomes found in numerous $\mathrm{AD}$ trials including some prior studies of $\mathrm{MAO}$ B inhibitors.

Neurofilament light chain (NfL) is another outcome measure that may become increasingly important in early-phase trials as a potential efficacy signal. NfL is considered a neuronal damage biomarker and is elevated in both blood and CSF in patients with symptomatic $\mathrm{AD}$ and $\mathrm{FTD}^{19}$ and in serum in patients with small vessel disease, which is a major cause of vascular cognitive impairment. ${ }^{20}$ In other neurologic diseases such as multiple sclerosis, ${ }^{21}$ and very recently, amyotrophic lateral sclerosis due to superoxide dismutase 1 mutation, ${ }^{22}$ reductions in CSF and blood NfL have been shown to correlate with clinical benefit. Because blood NfL correlates highly with changes in CSF NfL, serial blood samples can be used even when collection of CSF $\mathrm{NfL}$ is not feasible or when only a limited number of lumbar punctures can be performed. As a neuronal damage biomarker, reduction in NfL may provide evidence of a treatment's benefit regardless of the drug's putative mechanism of action on intermediate processes.

Clinically validated biomarkers that reflect other diverse targets like microglial dysfunction or autophagy are needed, and a growing number are currently in development for $\mathrm{AD} .^{23,24}$ There is an effort to expand the availability of biomarkers for FTD. Companies like Alector have used CSF and blood progranulin as pharmacodynamic readouts for its sortilin antibody trial, ${ }^{25}$ but more biomarkers for other genetic forms and sporadic forms of FTD will be required as new therapies move into the clinic. Novel target engagement and pharmacodynamic biomarkers should be developed in parallel to new candidate therapies in nonclinical development, and preliminary clinical validation data in the target population should be available before including new assays or imaging techniques as trial end points. It should be evident that the approach advocated in this article can be pursued only if biomarkers for the detection of pharmacodynamic effects are available and accepted by the development team as suitable for reaching development decisions to be implemented in exploratory trials. The inclusion of novel biomarkers in exploratory trials not only enhances our understanding of how a drug acts in humans but also adds to the clinical data package and often provides the rationale for dosage selection in subsequent studies. ${ }^{4}$ For instance, novel biomarkers that measure synaptic density or degeneration, including PET ligands like [ $\left.{ }_{11} \mathrm{C}\right]$ UCB-J, which labels synaptic vesicle glycoprotein $2 \mathrm{~A}$, and CSF markers like postsynaptic protein neurogranin have been included as exploratory end points in several ongoing studies. ${ }^{26,27}$ As with any clinical trial, the methodologies and analyses for all the biomarker end points must be prespecified to be trusted as valid reporters of biological activity. 
Although showing clinical efficacy may not be the main goal of an exploratory trial, the inclusion of cognitive and neuropsychological end points, particularly optimized clinical end points when selected and analyzed appropriately, ${ }^{28}$ may be informative as exploratory outcomes. The inclusion of clinical assessments also allows for estimation of correlation between biomarkers and clinical assessment, which can be useful for planning subsequent trials. As with biomarkers, selection of clinical end points should align with the therapeutic profile for the intervention. This includes scales that reflect the appropriate domain(s) for the clinical syndrome, stage of disease, and proposed mechanism of action of the test agent. Exploratory trials generally are not long enough or large enough to adequately detect differences in the traditional clinical outcomes used in phase $2 \mathrm{~b}$ and phase 3 trials, although expected directional changes that correlate with biomarker changes may be observed. Prespecified analyses that investigate the relationship between biomarker and clinical changes both at a study treatment level and patient level should be included in the analysis plan of exploratory studies. Alternatively, smaller exploratory trials offer the potential to identify early signals of negative clinical effects. The inclusion of computerized or app-based tests as exploratory end points may be considered at this stage. Digital cognitive and speechbased tests facilitate repeated assessments over shorter periods of time, which mitigates test learning effects, reduces noise associated with day-to-day within-subject variance, and improves study power. ${ }^{29}$ Some of these digital tests offer athome administration, which can ease patient, caregiver, and clinician burden as well as enable continuous monitoring. The emergence of the severe acute respiratory syndrome coronavirus 2 pandemic, which has sometimes prevented on-site study visits, has prompted accelerated development in this area. However, such unsupervised applications raise other difficulties where the test environment is difficult to control.

Determining the appropriate duration of exploratory trials for progressive diseases like $\mathrm{AD}$ and FTD depends on the expected rate of change for the primary study end points and the mechanism of action for the study drug. Historical data and disease modeling for the study outcomes can be used as references when data are available. Observational longitudinal studies like $\mathrm{ADNI}^{10}$ and the Australian Imaging Biomarkers and Lifestyle Study of Ageing ${ }^{30}$ offer a wealth of data on several imaging, fluid, and clinical end points. Although at an earlier stage, the FTD field is building on longitudinal data through multisite research consortia like the ALLFTD study ${ }^{11}$ and the GENFI network. ${ }^{12}$ Depending on the dementia subtype or stage, the time course to observe clinical benefits can be very different from that of biomarker outcomes. For instance, although group differences on the Alzheimer's Disease Assessment Scale-cognitive subscale in patients with mild to moderate $\mathrm{AD}$ may not be detected until 12 or 18 months of treatment, ${ }^{31}$ group differences on imaging biomarkers have been detected in patients with other neurodegenerative diseases in trials with much shorter treatment durations. In 1 example, microglial marker $18-\mathrm{kDa}$ translocator protein (TSPO), which is associated with neuroinflammation, was assessed in a study that tested the effect of myeloperoxidase inhibitor AZD3241 in patients with Parkinson disease. AZD3241 is hypothesized to reduce neuroinflammation through the reduction of oxidative stress. After 8 weeks of treatment, AZD3241 reduced TSPO binding across nigrostriatal regions, thereby supporting proof of mechanism and testing in a larger efficacy trial. ${ }^{32}$ Shorter treatment durations in exploratory trials based on biomarkers that are thought to change earlier than clinical outcomes may ultimately enable a more cost-effective and time-efficient clinical development program, as opposed to longer exploratory trials dependent on observing a signal on cognitive effects; time and cost savings will be dependent on the biomarker effect size and recruitment rates.

\section{Patient Population}

Because of the heterogeneity of $\mathrm{AD}$ and FTD with respect to clinical staging, rate of decline, and underlying pathologies, enrichment strategies might be considered for selecting the appropriate study population. Enrichment of patients by stage of severity, neuropathology, known genetics, clinical subtype, or other variables may reduce variability and increase the chances of detecting a positive signal related to the mechanism of action. For instance, hyperactivity in the hippocampus is observed in patients at the early stages of mild cognitive impairment (MCI) but not at later stages of the disease. ${ }^{33}$ AgeneBio, a CNS biopharmaceutical company, tested AGB101, a low-dose formulation of the antiepileptic drug levetiracetam, in an exploratory study for its effect on fMRI activation, specifically in patients with amnestic MCI (aMCI) rather than patients with more advanced stages of $\mathrm{AD} .^{34}$ Positive results from the exploratory study enriched with patients with aMCI (the population most likely to respond to a drug targeting hippocampal hyperactivity) led to an ongoing phase 3 study of AGB101 in participants with aMCI. ${ }^{35}$

For FTD trials, fully leveraging natural history data and using disease progression models can enable the identification of patients who are at a specific point in disease progression. This may allow for enriching the study population with patients who are more likely to progress in a predictable manner and who may experience the greatest effect from a treatment. Although adjusting for predicted progression in future studies may substantially increase power and help discern a difference between treatment and placebo groups, the historical data for FTD are still limited and may not reliably select the population most likely to respond to treatment. An alternative approach uses biomarkers. The NfL Surveillance Project, a precompetitive public-private consortium, is leveraging the ALLFTD study to qualify plasma NfL as a prognostic biomarker for prevention clinical trials in asymptomatic familial FTD participants who carry mutations in one of 3 genes (C9orf72, GRN, and MAPT). ${ }^{36}$ There are currently several drugs in clinical development that target one of these genetic 
causes and validating a biomarker that could identify people likely to become symptomatic could be used in prevention trials to treat gene carriers before the onset of symptoms. A recent study in this population showed that plasma NfL levels were elevated 2 years before the onset of symptoms and predicted future clinical status. ${ }^{36}$ Understanding the prognostic value of NfL in this population, particularly in asymptomatic patients, may enable the use of plasma NfL as a prognostic biomarker to enrich the enrollment for preclinical mutation carriers who are likely to convert to clinically symptomatic within the trial time frame and may be more likely to respond to treatment.

$\mathrm{AD}$ trials are increasingly using biomarker confirmation by amyloid PET or CSF amyloid- $\beta$ and tau to enrich the inclusion of patients with $\mathrm{AD} .^{37}$ The amyloid/tau/neurodegeneration ${ }^{38}$ framework provides a means of biological staging of $\mathrm{AD}$, as well as identifying disease-related outcomes for trials. ${ }^{39}$ Although trials for monogenic forms of FTD, which account for roughly $10 \%$ of cases, ${ }^{40}$ can use genetic markers as inclusion criteria, there is a lack of validated biomarkers that can diagnose sporadic forms of FTD. Beyond diagnosis, one can envision future trials that enrich patients by other pathologies common to both diseases that align with the proposed mechanism of actions for test agents. These include TAR DNA-binding protein 43, $a$-synuclein, inflammation, and mitochondrial dysfunction. ${ }^{41-43}$ INmuneBio, a clinical stage company focused on innate immunity, is taking this approach. They are developing a soluble tumor necrosis factor inhibitor that targets neuroinflammation in $\mathrm{AD}$ and are using biomarkers of inflammation as an enriching strategy for their phase $1 \mathrm{~b}$ trial. ${ }^{44}$ Although biomarkers could be used for targeted trials including patients exhibiting a shared pathology, the enrichment approach requires well-established biomarkers that are low cost, easily measurable, and have strong validation data in the target population. ${ }^{45}$

\section{Efficiency in Clinical Development}

Efficiency is essential in clinical development to advance a drug candidate into the clinic as soon as possible or alternatively to determine that it is ineffective so resources can be redeployed. ${ }^{46}$ Ticking patent clocks, competition, and financial/strategic considerations are all forces behind initiation of phase 3 trials without conclusive phase 2 study data or, in rare cases, skipping phase 2 altogether. ${ }^{47,48}$ Conducting several exploratory studies in parallel before moving into later phase studies may be 1 way to reduce clinical development timelines. For example, Cognition Therapeutics, a clinical stage company focused on therapies that displace amyloid- $\beta$ oligomers to protect synapses, is conducting 3 exploratory studies concurrently with its lead candidate, CT1812. The first is designed to show target engagement through displacement of CSF amyloid- $\beta$ oligomers after 48 hours. ${ }^{49}$ Another is a 6-month study evaluating changes in synaptic density with $\left[{ }_{11} \mathrm{C}\right] \mathrm{UCB}-\mathrm{J},{ }^{50}$ and the third is a 6-month study to provide initial safety and efficacy data. ${ }^{51}$ The parallel trial approach can build a rich data set by resolving key questions about the drug, while potentially saving time; feasibility of this approach will be dependent on available resources.

Newer efficiency approaches include the use of master protocols to evaluate multiple treatments and/or multiple diseases in a single coordinated protocol. In basket trials, a single therapy is assessed in different diseases or disease subtypes that share a common clinical or biological endophenotype. ${ }^{52}$ This is increasingly used in oncology where drugs are tested in patients with cancers harboring the same mutation but different tumor types. For a company with limited resources, this could serve as a useful approach to prioritize a primary disease indication for neurologic diseases. Oryzon Genomics, a clinical stage company developing epigenetic drugs, is using a basket trial design to test the effect of its drug, ORY-2001, on aggression in several psychiatric diseases. ${ }^{53}$ In a different example, a group at the University of California, San Francisco, tested a tau antibody in a phase $1 \mathrm{~b}$ basket trial with 4 primary tauopathy syndrome arms, including patients with variants of FTD spectrum disorders and traumatic encephalopathy syndromes. ${ }^{54}$

The platform trial is another type of master protocol where multiple drugs are tested in a single disease population, and drug arms can be added or removed based on a decision algorithm. ${ }^{52}$ Examples include the European Prevention of Alzheimer's Dementia proof-of-concept study, ${ }^{55}$ Dominantly Inherited Alzheimer's Network Trials Unit, ${ }^{56}$ and the HEALEY ALS Platform trial. ${ }^{57}$ Studies benefit from shared infrastructure and shared placebo arms, which increase statistical efficiency in terms of reduced sample size and power gains. ${ }^{58}$

Adaptive seamless studies may also increase the efficiency of clinical development. An exploratory study can be designed to have prespecified interim analysis adaptation rules to potentially stop the study early for futility, allow early graduation or transition to phase $2 b$, select the appropriate dose for the subsequent stage of the trial, or update randomization probabilities based on the optimal performing dose(s) and seamlessly integrate that dose(s) into a larger study. This works best with robust endpoints that achieve treatment effects within several months. Inferentially and operationally seamless study designs can increase study power by combining patients from both stages using the final dose, and it can optimize the duration of the trial by reducing the lag time between the 2 studies. The Intranasal Oxytocin for Frontotemporal Dementia trial is one such study, enrolling patients at multiple doses in the first stage with an interim analysis examining improvement in empathy deficits before moving to the second stage with the optimal dose. $^{59}$ These different approaches help to increase the efficiency of early-phase clinical development.

\section{Perspective}

The goal of exploratory studies is to make the most efficient use of available funds and limited time, building a robust body 
of biological evidence for how a drug affects a patient population, determining clear go/no-go decision points for whether a drug should be advanced or terminated, and using the accrued data to inform larger studies. The key recommendations for executing this approach include (1) leveraging rigorous statistical analyses/procedures and statisticians' expertise, (2) incorporating the appropriate endpoints (biomarker and clinical) that reflect the drug mechanism of action and specific study population, (3) leveraging historical data to determine appropriate outcomes that are well aligned with the disease and mechanism of action for the treatment, and (4) considering the use of novel clinical development plans to increase efficiency.

The examples discussed in this review mainly focused on small molecule and antibody therapies, but the key recommendations outlined here can be applied to the clinical development of emerging modalities, such as gene therapies and antisense oligonucleotide therapeutics. By targeting a specific gene, the selection of target engagement and downstream pharmacologic end points may be straightforward if relevant biomarkers already exist. However, nonpharmacologic interventions like transcranial stimulation paradigms, which have been recently tested in patients with $\mathrm{AD}$ and FTD, do not have defined molecular mechanisms of action. Therefore, functional biomarker measures such as EEG and FDG-PET may be considered as exploratory trial endpoints.

Table 2 summarizes the differences between exploratory and later-phase trials. The majority of costs in clinical development come from phase 3 studies. $^{60}$ The real cost of incorporating the exploratory trial approach is comparatively small, making this a critical inflection point for terminating programs that are not likely to succeed and recovering the opportunity cost for those that are more promising. One risk in exploratory studies may come from cognitive biases, where stakeholders that are heavily invested in a particular therapeutic may misinterpret results and decide that larger clinical trials are warranted even in the absence of convincing data. Although biotechnology companies or academic groups may be averse to terminating their lead asset, ending programs early that are not likely to succeed will benefit all stakeholders, including investors, patients, and other companies that need access to valuable patient populations. ${ }^{47}$ However, one must balance the risk of moving forward with programs likely to fail with the risk of terminating programs that might succeed. This may be especially difficult for biotechnology companies with few assets under development and an incentive to keep the company going at all costs. In the long run, and for the $\mathrm{AD}$ and $\mathrm{FTD}$ ecosystems as a whole, incremental advancement through a clinical development program with early exploratory studies, if done well, can improve the understanding of the clinical profile of a drug and increase the chance of future success.

\section{Acknowledgment}

All authors were participants of an advisory panel focused on optimizing exploratory trial designs for Alzheimer disease and frontotemporal dementias and were convened by the Alzheimer's Drug Discovery Foundation and the Association for Frontotemporal Degeneration. The authors thank Nadine Tatton, $\mathrm{PhD}$ (of Alector and formerly of the Association for Frontotemporal Degeneration) for guidance in planning the advisory panel.

\section{Study Funding}

This article and the corresponding advisory panel were supported by the Alzheimer's Drug Discovery Foundation and the Association for Frontotemporal Degeneration.

\section{Disclosure}

L.G. Friedman, N. McKeehan, and Y. Hara report no disclosures relevant to the manuscript. J.L. Cummings has provided consultation to Acadia, Actinogen, Acumen, Alector, Alkahest, Alzheon, AriBio, Avanir, Axsome, Behren Therapeutics, Biogen, Cassava, Cerecin, Cerevel, Cortexyme, Cytox, EIP Pharma, Eisai, Foresight, GemVax, Genentech, Green Valley, Grifols, Janssen, Karuna, Merck, Novo Nordisk, Otsuka, ReMYND, Resverlogix, Roche, Samumed, Samus, Signant Health, Sunovion, Suven, and United Neuroscience pharmaceutical and assessment companies; has stock options in ADAMAS, AnnovisBio, MedAvante, and BiOasis; owns the copyright of the Neuropsychiatric Inventory; and is supported by NIGMS grant P20GM109025, NINDS grant U01NS093334, NIA grant R01AG053798, and NIA grant P20AG068053. D.C. Matthews is the Chief Executive Officer of ADM Diagnostics. J. Zhu is an employee of Servier Pharmaceuticals and owns stocks of Takeda Pharmaceuticals. R. C. Mohs is the Chief Science Officer for the Global Alzheimer's Platform Foundation and the Vice President for Clinical Development at AgeneBio, Inc.; serves as a member of the Board of Directors for Cogstate, Ltd.; holds stock in Cogstate; has received consulting fees from United Neuroscience, Inc. and Neurobio, Inc; is an uncompensated member of the Board of Directors of the Alzheimer's Drug Discovery Foundation; and was previously an employee of Eli Lilly and Company and holds stock in Lilly. D. Wang and S.B. Hendrix report no disclosures relevant to the manuscript. M. Quintana is an employee of Berry Consultants, LLC where she serves as a consultant to numerous pharmaceutical and device companies. L.S. Schneider reports reimbursement for travel expenses from the Alzheimers Drug Discovery Foundation during the conduct of the study, grants/contracts and personal fees from Eli Lilly, Merck, Roche/Genentech, grants/contracts from Biogen, Biohaven, Cortexyme, Novartis, and Washington University/NIA DIAN-TU, and personal fees from Abbott, AC Immune, Avraham, Ltd, Boehringer Ingelheim, Cognition Therapeutics, Eisai, FujiFilm, Immunobrain Checkpoint Ltd, Neurim Ltd, Neuronix Ltd, Samus, and Takeda outside of and within 2 years of the submitted. M. 
Grundman received reimbursement for travel expenses from the Alzheimer's Drug Discovery Foundation during the conduct of the study and has been a paid consultant to AbbVie, Adamas, AgeneBio, Annexon, AnnovisBio, AstraZeneca, Biogen, Biohaven, Bristol-Myers Squibb, Cerespir, Cognition Therapeutics, E-scape, Johnson \& Johnson, Kalgene, Lilly, Neurelis, Neurovision, Neuron23, Otsuka, Proclara, Prothena, Samumed, Transposon Therapeutics, and Ultragenyx. S.P. Dickson reports no disclosures relevant to the manuscript. H. H. Feldman discloses UCSD service agreements for consulting on Alzheimer disease or other dementias with Axon Neuroscience, Banner Health, Roche/ Genentech (DMC and DSMB), Samus Therapeutics, Tau Consortium, and Novo Nordisk, ADCS Clinical Trials grant funding from Annovis (Posiphen), Biohaven (BH 4157), Vivoryon (PQ912), AC Immune (ACI-24- 1301), LuMind (ADC-059-LIFE-DSR), and Research funding from NIA/ NIH (U19 AG010483, R01 AG061146-01, R01 AG051618, R01 AG047922, and 1R56AG069130-01), CIHR (137794, 254450), Brain Canada (4469), and Alzheimer's Association (SG-20-690388-PEACE AD). J. Jaeger is owner of CognitionMetrics, LLC, which has provided scientific consultation to Aptinyx, Acadia, AstraZeneca, Axsome, Biogen, Boehringer-Ingelheim, Collegium, Eisai, Forum, Harmony, INmune, IProteos, Janssen, Jazz, Lundbeck, Otsuka, Ovid, Perception, Pfizer, Sunovion, Syndesi, Takeda, and Teva. E. C. Finger has received personal compensation for serving on a PSP Scientific Advisory or Data Safety Monitoring board for Biogen, for serving as a section editor for NeuroImage Clinical, and for serving as a course director for the AAN Annual Meeting and has received research support paid to her institution (UWO) from the CIHR, the Weston Foundation, Alzheimer Society of Canada, and the Physicians and Services Incorporated Foundation, the Ministry of Research and Innovation of Ontario and for site participation in clinical trials sponsored by Alector, Biogen, and TauRx; J. M. Ryan, D. Niehoff, and S.L.-J. Dickinson report no disclosures relevant to the manuscript. J.T. Markowitz is an employee of Modus Outcomes, which provides consulting services to the pharmaceutical industry. M. Owen and A. Travaglia report no disclosures relevant to the manuscript. H. M. Fillit is a paid consultant to Alector, Biogen, vTv, Lundbeck/Otsuka, and Samus and an unpaid consultant to Lilly; the Alzheimer's Drug Discovery Foundation has funded or cofunded several projects to develop or clinically test the following drugs or biomarker programs that are discussed in the manuscript: AGB101, CT1812, NfL Surveillance Project, ORY-2001, and rasagiline; the Association for Frontotemporal Degeneration has cofunded the NfL Surveillance Project discussed in the manuscript. Go to Neurology.org/N for full disclosures.

\section{Publication History}

Received by Neurology October 22, 2020. Accepted in final form February 12, 2021.

\section{Appendix Authors}

\begin{tabular}{|c|c|c|}
\hline Name & Location & Contribution \\
\hline $\begin{array}{l}\text { Lauren G. } \\
\text { Friedman, } \\
\text { PhD }\end{array}$ & $\begin{array}{l}\text { Alzheimer's Drug Discovery } \\
\text { Foundation, New York }\end{array}$ & $\begin{array}{l}\text { Drafted and revised } \\
\text { the manuscript for } \\
\text { intellectual content }\end{array}$ \\
\hline $\begin{array}{l}\text { Nicholas } \\
\text { McKeehan, BS }\end{array}$ & $\begin{array}{l}\text { Alzheimer's Drug Discovery } \\
\text { Foundation, New York }\end{array}$ & $\begin{array}{l}\text { Drafted and revised } \\
\text { the manuscript for } \\
\text { intellectual content }\end{array}$ \\
\hline $\begin{array}{l}\text { Yuko Hara, } \\
\text { PhD }\end{array}$ & $\begin{array}{l}\text { Alzheimer's Drug Discovery } \\
\text { Foundation, New York }\end{array}$ & $\begin{array}{l}\text { Revised the } \\
\text { manuscript for } \\
\text { intellectual content }\end{array}$ \\
\hline $\begin{array}{l}\text { Jeffrey L. } \\
\text { Cummings, } \\
\text { MD, ScD }\end{array}$ & $\begin{array}{l}\text { University of Nevada, Las } \\
\text { Vegas, Las Vegas }\end{array}$ & $\begin{array}{l}\text { Revised the } \\
\text { manuscript for } \\
\text { intellectual content }\end{array}$ \\
\hline $\begin{array}{l}\text { Dawn C. } \\
\text { Matthews, } \\
\text { MS, MBA }\end{array}$ & $\begin{array}{l}\text { ADM Diagnostics, Inc., } \\
\text { Northbrook, IL }\end{array}$ & $\begin{array}{l}\text { Revised the } \\
\text { manuscript for } \\
\text { intellectual content }\end{array}$ \\
\hline Jian Zhu, PhD & $\begin{array}{l}\text { Servier Pharmaceuticals, } \\
\text { Boston, MA }\end{array}$ & $\begin{array}{l}\text { Revised the } \\
\text { manuscript for } \\
\text { intellectual content }\end{array}$ \\
\hline $\begin{array}{l}\text { Richard C. } \\
\text { Mohs, PhD }\end{array}$ & $\begin{array}{l}\text { Global Alzheimer's Platform } \\
\text { Foundation, Washington, DC; } \\
\text { AgeneBio, Inc., Baltimore, } \\
\text { MD }\end{array}$ & $\begin{array}{l}\text { Revised the } \\
\text { manuscript for } \\
\text { intellectual content }\end{array}$ \\
\hline $\begin{array}{l}\text { Deli Wang, } \\
\text { MMed, PhD }\end{array}$ & AbbVie Inc, North Chicago, IL & $\begin{array}{l}\text { Revised the } \\
\text { manuscript for } \\
\text { intellectual content }\end{array}$ \\
\hline $\begin{array}{l}\text { Suzanne B. } \\
\text { Hendrix, PhD }\end{array}$ & $\begin{array}{l}\text { Pentara Corporation, Salt } \\
\text { Lake City, UT }\end{array}$ & $\begin{array}{l}\text { Revised the } \\
\text { manuscript for } \\
\text { intellectual content }\end{array}$ \\
\hline $\begin{array}{l}\text { Melanie } \\
\text { Quintana, } \\
\text { PhD }\end{array}$ & Berry Consultants, Austin, TX & $\begin{array}{l}\text { Revised the } \\
\text { manuscript for } \\
\text { intellectual content }\end{array}$ \\
\hline $\begin{array}{l}\text { Lon S. } \\
\text { Schneider, } \\
\text { MD }\end{array}$ & $\begin{array}{l}\text { University of Southern } \\
\text { California, Los Angeles }\end{array}$ & $\begin{array}{l}\text { Revised the } \\
\text { manuscript for } \\
\text { intellectual content }\end{array}$ \\
\hline $\begin{array}{l}\text { Michael } \\
\text { Grundman, } \\
\text { MD, MPH }\end{array}$ & $\begin{array}{l}\text { Global R\&D Partners, LLC, } \\
\text { San Diego; University of } \\
\text { California, San Diego, La Jolla }\end{array}$ & $\begin{array}{l}\text { Revised the } \\
\text { manuscript for } \\
\text { intellectual content }\end{array}$ \\
\hline $\begin{array}{l}\text { Samuel P. } \\
\text { Dickson, PhD }\end{array}$ & $\begin{array}{l}\text { Pentara Corporation, Salt } \\
\text { Lake City, UT }\end{array}$ & $\begin{array}{l}\text { Revised the } \\
\text { manuscript for } \\
\text { intellectual content }\end{array}$ \\
\hline $\begin{array}{l}\text { Howard H. } \\
\text { Feldman, } \\
\text { MDCM, } \\
\text { FRCP(C) }\end{array}$ & $\begin{array}{l}\text { University of California, San } \\
\text { Diego, La Jolla }\end{array}$ & $\begin{array}{l}\text { Revised the } \\
\text { manuscript for } \\
\text { intellectual content }\end{array}$ \\
\hline $\begin{array}{l}\text { Judith Jaeger, } \\
\text { PhD }\end{array}$ & $\begin{array}{l}\text { Albert Einstein College of } \\
\text { Medicine, Bronx, NY; } \\
\text { CognitionMetrics, LLC }\end{array}$ & $\begin{array}{l}\text { Revised the } \\
\text { manuscript for } \\
\text { intellectual } \\
\text { content }\end{array}$ \\
\hline $\begin{array}{l}\text { Elizabeth C. } \\
\text { Finger, MD }\end{array}$ & $\begin{array}{l}\text { University of Western } \\
\text { Ontario, London, Canada; } \\
\text { Parkwood Institute, Lawson } \\
\text { Health Research Institute, St. } \\
\text { Joseph's Health Care, } \\
\text { London, Canada }\end{array}$ & $\begin{array}{l}\text { Revised the } \\
\text { manuscript for } \\
\text { intellectual content }\end{array}$ \\
\hline $\begin{array}{l}\text { J. Michael } \\
\text { Ryan, MD }\end{array}$ & $\begin{array}{l}\text { Rodin Therapeutics, Boston, } \\
\text { MA }\end{array}$ & $\begin{array}{l}\text { Revised the } \\
\text { manuscript for } \\
\text { intellectual content }\end{array}$ \\
\hline
\end{tabular}


Appendix (continued)

\begin{tabular}{lll}
\hline Name & Location & Contribution \\
\hline $\begin{array}{l}\text { Debra } \\
\text { Niehoff, PhD }\end{array}$ & $\begin{array}{l}\text { Association for } \\
\text { Frontotemporal } \\
\text { Degeneration, Radnor, PA }\end{array}$ & $\begin{array}{l}\text { Revised the } \\
\text { manuscript for } \\
\text { intellectual content }\end{array}$ \\
\hline $\begin{array}{l}\text { Susan L-J. } \\
\text { Dickinson, } \\
\text { MSGC }\end{array}$ & $\begin{array}{l}\text { Association for } \\
\text { Frontotemporal }\end{array}$ & $\begin{array}{l}\text { Revised the } \\
\text { manuscript for } \\
\text { intellectual content }\end{array}$ \\
\hline $\begin{array}{l}\text { Jessica T. } \\
\text { Markowitz, }\end{array}$ & Modus Outcomes LLP, & $\begin{array}{l}\text { Revised the } \\
\text { manuscript for } \\
\text { intellectual content }\end{array}$ \\
\hline $\begin{array}{l}\text { Meriel Owen, } \\
\text { PhD }\end{array}$ & Alzheimer's Drug Discovery & $\begin{array}{l}\text { Revised the } \\
\text { manuscript for } \\
\text { intellectual content }\end{array}$ \\
\hline $\begin{array}{l}\text { Alessio } \\
\text { Travaglia, } \\
\text { PhD }\end{array}$ & Foundation, New York & Foundation, New York \\
\hline $\begin{array}{l}\text { Howard M. } \\
\text { Fillit, MD }\end{array}$ & Alzheimer's Drug Discovery & $\begin{array}{l}\text { Revised the } \\
\text { manuscript for } \\
\text { intellectual content }\end{array}$ \\
\hline
\end{tabular}

\section{References}

1. Alzheimer's Disease International. World Alzheimer Report 2019: attitudes to dementia [online]. Available at: alz.co.uk/research/WorldAlzheimerReport2019.pdf. Accessed August 7, 2020.

2. Petersen RC, Thomas RG, Aisen PS, et al. Randomized controlled trials in mild cognitive impairment: sources of variability. Neurology. 2017;88:1751-1758.

3. Cummings JL, Morstorf T, Zhong K. Alzheimer's disease drug-development pipeline: few candidates, frequent failures. Alzheimers Res Ther. 2014;6:37.

4. Scott TJ, O'Connor AC, Link AN, Beaulieu TJ. Economic analysis of opportunities to accelerate Alzheimer's disease research and development. Ann N Y Acad Sci. 2014; 1313:17-34.

5. Prasad V, Mailankody S. Research and development spending to bring a single cance drug to market and revenues after approval. JAMA Intern Med. 2017;177:1569-1575.

6. Boxer AL, Gold M, Feldman $\mathrm{H}$, et al. New directions in clinical trials for frontotemporal lobar degeneration: methods and outcome measures. Alzheimers Dement. 2020;16:131-143.

7. Krystal AD, Pizzagalli DA, Smoski M, et al. A randomized proof-of-mechanism tria applying the 'fast-fail' approach to evaluating kappa-opioid antagonism as a treatment for anhedonia. Nat Med. 2020;26:760-768.

8. Owens PK, Raddad E, Miller JW, et al. A decade of innovation in pharmaceutical R\&D: the Chorus model. Nat Rev Drug Discov. 2015;14:17-28.

9. Lo AW, Ho C, Cummings J, Kosik KS. Parallel discovery of Alzheimer's therapeutics. Sci Transl Med. 2014;6:3008228.

10. Weiner MW, Veitch DP, Aisen PS, et al. Recent publications from the Alzheimer's Disease Neuroimaging Initiative: reviewing progress toward improved $\mathrm{AD}$ clinical trials. Alzheimers Dement. 2017;13:e1-e85.

11. Boeve B, Bove J, Brannelly P, et al. The longitudinal evaluation of familial frontotemporal dementia subjects protocol: framework and methodology. Alzheimers Dement. 2020;16:22-36.

12. Mutsaerts H, Petr J, Thomas DL, et al. Comparison of arterial spin labeling registration strategies in the multi-center GENetic frontotemporal dementia initiative (GENFI). J Magn Reson Imaging. 2018;47:131-140.

13. Ciolino JD, Martin RH, Zhao W, Hill MD, Jauch EC, Palesch YY. Measuring continuous baseline covariate imbalances in clinical trial data. Stat Methods Med Res. 2015;24:255-272.

14. Wang D, Li Y, Wang X, et al. Overview of multiple testing methodology and recent development in clinical trials. Contemp Clin Trials. 2015;45:13-20.

15. Satlin A, Wang J, Logovinsky V, et al. Design of a Bayesian adaptive phase 2 proof-ofconcept trial for BAN2401, a putative disease-modifying monoclonal antibody for the treatment of Alzheimer's disease. Alzheimers Dement (N Y). 2016;2:1-12.

16. Food, Drug Administration. Interacting with the FDA on complex innovative trial designs for drugs and biological products [online]. Available at: fda.gov/media/ 130897/download. Accessed September 13, 2020.

17. Cummings J. The role of biomarkers in Alzheimer's disease drug development. Adv Exp Med Biol. 2019;1118:29-61.

18. Matthews D, Ritter A, Thomas R, et al. The Effects of Rasagiline upon cerebral glucose metabolism, cognition, and tau in patients with mild to moderate Alzheimer's disease. Presented at the 12th Clinical Trials on Alzheimer's Disease conference, December 6, 2019, San Diego.

19. Forgrave LM, Ma M, Best JR, DeMarco ML. The diagnostic performance of neurofilament light chain in CSF and blood for Alzheimer's disease, frontotemporal dementia, and amyotrophic lateral sclerosis: a systematic review and meta-analysis. Alzheimers Dement (Amst). 2019;11:730-743.

20. Duering M, Konieczny MJ, Tiedt S, et al. Serum neurofilament light chain levels are related to small vessel disease burden. J Stroke. 2018;20:228-238.

21. Delcoigne B, Manouchehrinia A, Barro C, et al. Blood neurofilament light levels segregate treatment effects in multiple sclerosis. Neurology. 2020;94:e1201-e1212.

22. Miller T, Cudkowicz M, Shaw PJ, et al. Phase 1-2 trial of antisense oligonucleotide tofersen for SOD1 ALS. N Engl J Med. 2020;383:109-119.

23. Park SA, Han SM, Kim CE. New fluid biomarkers tracking non-amyloid-beta and nontau pathology in Alzheimer's disease. Exp Mol Med. 2020;52:556-568.

24. Marquez F, Yassa MA. Neuroimaging biomarkers for Alzheimer's disease. Mol Neurodegener. 2019;14:21

25. Paul R, Ward M, Siddiqui O, et al. A phase 1 study of AL001 in healthy volunteers and frontotemporal dementia patients carrying a granulin mutation. Presented at the Alzheimer's Association International Conference, July 17, 2019, Los Angeles.

26. Colom-Cadena M, Spires-Jones T, Zetterberg H, et al. The clinical promise of biomarkers of synapse damage or loss in Alzheimer's disease. Alzheimers Res Ther. 2020; $12: 21$.

27. Schneider LS, Caggiano AO, Grundman M, et al. Clinical biomarker evidence for target engagement, reduction of synaptic damage and disease modification in $\mathrm{Alz}$ heimer's patients treated with CT1812. Presented at the Alzheimer's Association International Conference, July 17, 2019, Los Angeles.

28. Hendrix SB. Measuring clinical progression in MCI and pre-MCI populations: enrichment and optimizing clinical outcomes over time. Alzheimers Res Ther. 2012;4:24.

29. Gold M, Amatniek J, Carrillo MC, et al. Digital technologies as biomarkers, clinical outcomes assessment, and recruitment tools in Alzheimer's disease clinical trials. Alzheimers Dement (N Y). 2018;4:234-242.

30. Ellis KA, Bush AI, Darby D, et al. The Australian Imaging, Biomarkers and Lifestyle (AIBL) study of aging: methodology and baseline characteristics of 1112 individuals recruited for a longitudinal study of Alzheimer's disease. Int Psychogeriatr. 2009;21: 672-687.

31. Schneider LS, Mangialasche F, Andreasen N, et al. Clinical trials and late-stage drug development for Alzheimer's disease: an appraisal from 1984 to 2014. J Intern Med. 2014;275:251-283.

32. Jucaite A, Svenningsson P, Rinne JO, et al. Effect of the myeloperoxidase inhibitor AZD3241 on microglia: a PET study in Parkinson's disease. Brain. 2015;138 2687-2700.

33. Celone KA, Calhoun VD, Dickerson BC, et al. Alterations in memory networks in mild cognitive impairment and Alzheimer's disease: an independent component analysis. J Neurosci. 2006;26:10222-10231.

34. Bakker A, Albert MS, Krauss G, Speck CL, Gallagher M. Response of the medial temporal lobe network in amnestic mild cognitive impairment to therapeutic intervention assessed by fMRI and memory task performance. Neuroimage Clin. 2015; 7:688-698.

35. Study of AGB101 in mild cognitive impairment due to Alzheimer's disease (HOPE4MCI) [online]. Available at: clinicaltrials.gov/ct2/show/NCT03486938. Accessed August 20, 2020.

36. van der Ende EL, Meeter LH, Poos JM, et al. Serum neurofilament light chain in genetic frontotemporal dementia: a longitudinal, multicentre cohort study. Lancet Neurol. 2019;18:1103-1111.

37. Dubois B, Feldman HH, Jacova C, et al. Advancing research diagnostic criteria for Alzheimer's disease: the IWG-2 criteria. Lancet Neurol. 2014;13:614-629.

38. Jack CR Jr., Bennett DA, Blennow K, et al. NIA-AA Research Framework: toward a biological definition of Alzheimer's disease. Alzheimers Dement. 2018;14:535-562.

39. Cummings J. The National Institute on Aging-Alzheimer's Association Framework on Alzheimer's disease: application to clinical trials. Alzheimers Dement. 2019;15:172-178.

40. Turner MR, Al-Chalabi A, Chio A, et al. Genetic screening in sporadic ALS and FTD. J Neurol Neurosurg Psychiatry. 2017;88:1042-1044.

41. Boyle PA, Yu L, Leurgans SE, et al. Attributable risk of Alzheimer's dementia at tributed to age-related neuropathologies. Ann Neurol. 2019;85:114-124.

42. Mandrekar-Colucci S, Landreth GE. Microglia and inflammation in Alzheimer's disease. CNS Neurol Disord Drug Targets. 2010;9:156-167.

43. Wang W, Zhao F, Ma X, Perry G, Zhu X. Mitochondria dysfunction in the pathogenesis of Alzheimer's disease: recent advances. Mol Neurodegener. 2020;15:30

44. A biomarker-directed study of XPro1595 in patients with mild to moderate Alzheimer's [online]. Available at: clinicaltrials.gov/ct2/show/NCT03943264. Accessed August 23, 2020.

45. Mattsson N, Carrillo MC, Dean RA, et al. Revolutionizing Alzheimer's disease and clinical trials through biomarkers. Alzheimers Dement (Amst). 2015;1:412-419.

46. Paul SM, Mytelka DS, Dunwiddie CT, et al. How to improve R\&D productivity: the pharmaceutical industry's grand challenge. Nat Rev Drug Discov. 2010;9:203-214.

47. Gold M. Phase II clinical trials of anti-amyloid beta antibodies: when is enough, enough?. Alzheimers Dement (N Y). 2017;3:402-409.

48. Egan MF, Kost J, Tariot PN, et al. Randomized trial of verubecestat for mild-tomoderate Alzheimer's disease. N Engl J Med. 2018;378:1691-1703.

49. Study to evaluate the effect of CT1812 treatment on amyloid beta oligomer displacement into CSF in subjects with mild to moderate Alzheimer's disease [online] Available at: clinicaltrials.gov/ct2/show/NCT03522129. Accessed May 27, 2020.

50. Effect of CT1812 treatment on Brain synaptic density [online]. Available at: clinicaltrials.gov/ct2/show/NCT03493282. Accessed February 27, 2020.

51. A study to evaluate the safety and efficacy of CT1812 in subjects with mild to moderate Alzheimer's disease. [online]. Available at: clinicaltrials.gov/ct2/show/ NCT03507790. Accessed May 27, 2020. 
52. Woodcock J, LaVange LM. Master protocols to study multiple therapies, multiple diseases, or both. N Engl J Med. 2017;377:62-70.

53. Oryzon Genomics SA. ORYZON presents new positive REIMAGINE efficacy data of vafidemstat in the treatment of aggression [online]. Available at: globenewswire.com/ news-release/2019/10/03/1924660/0/en/ORYZON-Presents-New-Positive-REIMAGINE-Efficacy-Data-of-Vafidemstat-in-the-Treatment-of-Aggression.html. Accessed May 27, 2020

54. BIIB092 in Primary Tauopathies: CBS, nfvPPA, sMAPT, and TES (TauBasket) [online]. Available at: clinicaltrials.gov/ct2/show/NCT03658135. Accessed May 27, 2020.

55. Ritchie CW, Muniz-Terrera G, Kivipelto M, Solomon A, Tom B, Molinuevo JL. The European prevention of Alzheimer's dementia (EPAD) longitudinal cohort study: baseline data release V500.0. J Prev Alzheimers Dis. 2020;7:8-13.
56. Bateman RJ, Benzinger TL, Berry S, et al. The DIAN-TU Next Generation Alzheimer's prevention trial: adaptive design and disease progression model. Alzheimers Dement. 2017;13:8-19.

57. HEALEY ALS platform trial - master protocol [online]. Available at: clinicaltrials.gov/ ct2/show/NCT04297683. Accessed September 15, 2020.

58. Saville BR, Berry SM. Efficiencies of platform clinical trials: a vision of the future. Clin Trials. 2016;13:358-366

59. Finger E, Berry S, Cummings J, et al. Adaptive crossover designs for assessment of symptomatic treatments targeting behaviour in neurodegenerative disease: a phase 2 clinical trial of intranasal oxytocin for frontotemporal dementia (FOXY). Alzheimers Res Ther. 2018;10:102.

60. DiMasi JA, Grabowski HG, Hansen RW. Innovation in the pharmaceutical industry: new estimates of R\&D costs. J Health Econ. 2016;47:20-33.

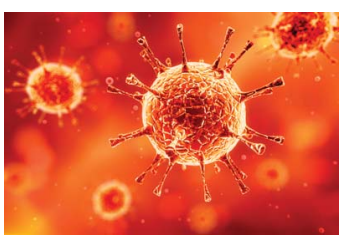

\section{COVID-19 and Neurologic Disease: Call for Papers!}

The editors of Neurology are interested in papers that address the neurological aspects of COVID-19 infection and challenges to the management of patients with chronic neurological conditions who have, or are at risk for, the infection. Relevant papers that pass initial internal review will undergo expedited peer review and online publication. We will consider papers posted in preprint servers.

Submit observational studies and clinical trials as Articles and case series and case reports under the Clinical/Scientific Notes category to https://submit.neurology.org/ today!

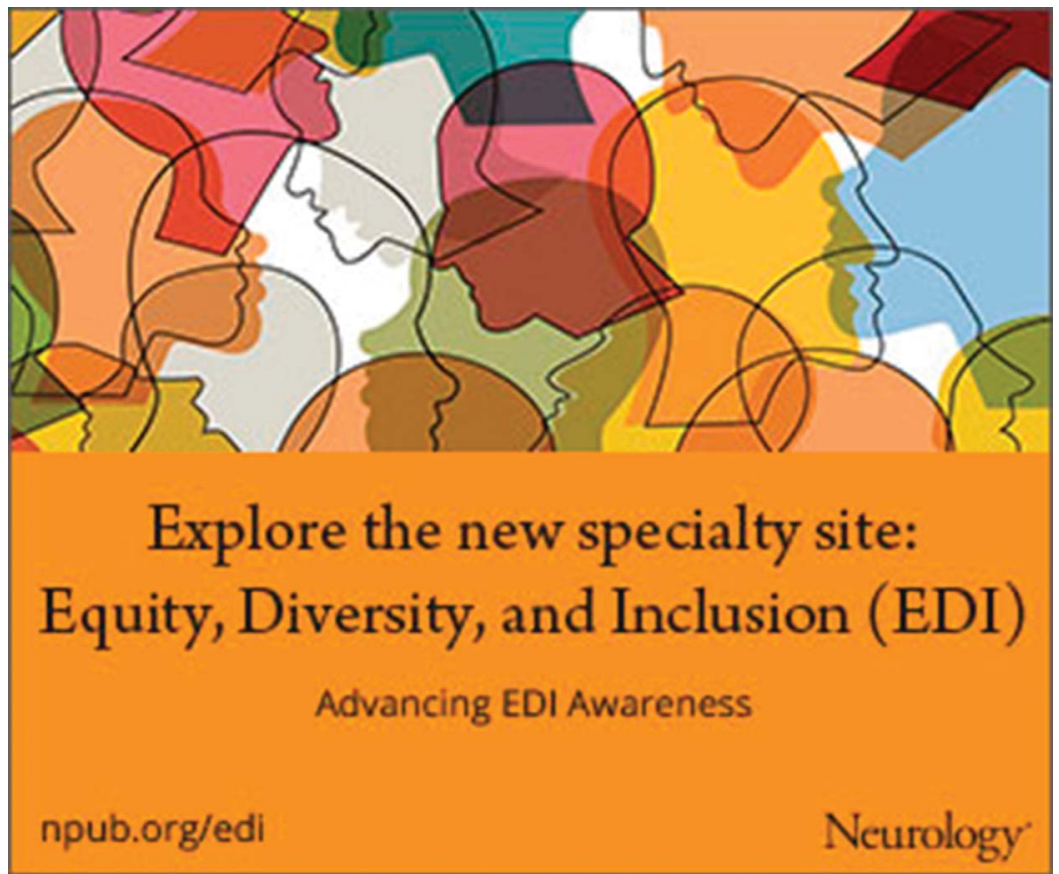




\section{Neurology}

\section{Value-Generating Exploratory Trials in Neurodegenerative Dementias \\ Lauren G. Friedman, Nicholas McKeehan, Yuko Hara, et al.}

Neurology 2021;96;944-954 Published Online before print March 5, 2021

DOI 10.1212/WNL.0000000000011774

This information is current as of March 5, 2021

Updated Information \& Services

References

Subspecialty Collections

Permissions \& Licensing

Reprints including high resolution figures, can be found at: http://n.neurology.org/content/96/20/944.full

This article cites 47 articles, 4 of which you can access for free at: http://n.neurology.org/content/96/20/944.full\#ref-list-1

This article, along with others on similar topics, appears in the following collection(s):

All Cognitive Disorders/Dementia

http://n.neurology.org/cgi/collection/all_cognitive_disorders_dementia Alzheimer's disease

http://n.neurology.org/cgi/collection/alzheimers_disease

Clinical trials Methodology/study design

http://n.neurology.org/cgi/collection/clinical_trials_methodology_study design

$\overline{\text { Frontotemporal dementia }}$

http://n.neurology.org/cgi/collection/frontotemporal_dementia

Information about reproducing this article in parts (figures,tables) or in its entirety can be found online at:

http://www.neurology.org/about/about_the_journal\#permissions

Information about ordering reprints can be found online:

http://n.neurology.org/subscribers/advertise

Neurology ${ }^{\circledR}$ is the official journal of the American Academy of Neurology. Published continuously since 1951, it is now a weekly with 48 issues per year. Copyright Copyright (C) 2021 The Author(s). Published by Wolters Kluwer Health, Inc. on behalf of the American Academy of Neurology.. All rights reserved. Print ISSN: 0028-3878. Online ISSN: 1526-632X.

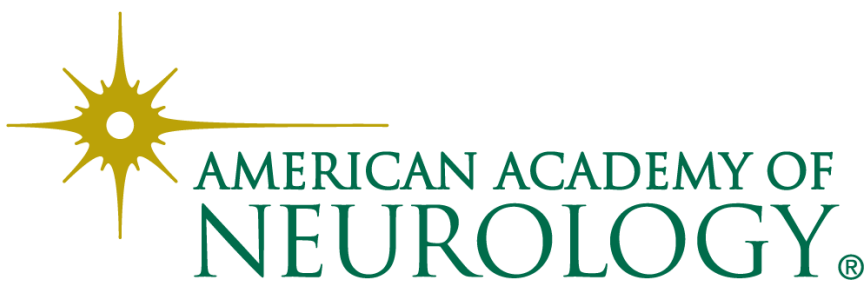

